\title{
Análise do desempenho de ligações por meio de emenda com dispositivo metálico parafusado em pilares pré-moldados de concreto
}

\author{
Performance analysis of column-to-column \\ connections using steel shoe splices \\ in precast concrete structures
}

João Lucas Figueiredo Paes de Barros ${ }^{1}$, Bruna Catoia ${ }^{1}$, Marcelo de Araújo Ferreira ${ }^{1}$

\begin{abstract}
${ }^{1}$ Núcleo de Estudo e Tecnologia em Pré-moldados de Concreto (NETPre). Departamento de Engenharia Civil da Universidade Federal de São Carlos - Deciv/UFSCar, Rod. Washington Luis, km 235 - CEP:13565-905, São Carlos, SP, Brasil. e-mail: jlpaesdebarros@gmail.com, bcatoia@yahoo.com.br, marceloaferreira@uol.com.br
\end{abstract}

\section{RESUMO}

As estruturas pré-moldadas de concreto são, convencionalmente no Brasil, sistemas de pórticos não contraventados com pilares contínuos. Sendo os pilares responsáveis pelo fornecimento de estabilidade lateral e transporte dos carregamentos verticais. A necessidade de emendas em pilares pré-fabricados de concreto surge da adoção crescente do sistema em edificações de múltiplos pavimentos e das limitações logísticas relativas às dimensões das peças, como transporte e içamento. Uma solução para o problema é fornecer continuidade ao pilar pré-moldado por meio de ligações de continuidade. O objetivo principal do trabalho consiste em analisar o desempenho em serviço (rigidez) de ligações por meio de emenda com dispositivo metálico. Para isso foram projetados e ensaiados à flexão (quatro pontos) dois modelos: um modelo monolítico (referência) e um modelo segmentado com ligações parafusadas. Os deslocamentos verticais medidos nos modelos foram utilizados para determinação de parâmetros de rigidez equivalente, curvatura e flecha. A partir do estudo realizado pôde-se concluir que o modelo com ligação parafusada (LB-PAR) apresentou comportamento bastante próximo do modelo monolítico de referência (MB) até cerca de $80 \%$ da força que produz o momento fletor relativo ao limite de escoamento. Conclui-se que o desempenho da ligação foi satisfatório, sendo possível sua utilização em obras correntes desde que observadas as restrições de uso em casos específicos de edificações em que o comportamento global da estrutura é significativamente influenciado pelos efeitos de segunda ordem.

Palavras-chave: Estruturas pré-moldadas, ligação equivalente, rigidez de ligações, sapatas metálicas, ligações de continuidade.

\begin{abstract}
Precast concrete structures in Brazil are usually unbraced with continuous columns. Which are responsible for the lateral stability and vertical load transfer. With the growing use of precast concrete structures in multistorey buildings arises a need for moment-resisting connections in the concrete columns, explained by the logistical difficulties of transport and assembly. Moment-resisting connections are a solution to counteract the logistical shortcomings. The main focus of this paper consists in analyzing the connection's mechanical behavior under service loads. In order to achieve this goal two full scale models were built and tested (four point bending): one cast-in-situ column and one connected using steel shoes. The measured displacements were used to determine the equivalent stiffness, curvature, and deflection. From this research it's possible to assert that the model with bolted connections (LB-PAR) displays similar behavior to the cast-in-situ model up until $80 \%$ of the load that causes the rebar to yield. The mechanical behavior of the connection is considered satisfactory for regular use, since the restrictions to the use are observed in the specific cases in which the structural behaviour is significantly influenced by second order effects.
\end{abstract}

Keywords: Precast concrete structures, equivalent connection, connections stiffness, steel shoes, momentresisting connections. 


\section{INTRODUÇÃO}

As estruturas pré-moldadas de concreto são, convencionalmente no Brasil, sistemas de pórticos não contraventados com pilares contínuos. Sendo os pilares então responsáveis pelo fornecimento de estabilidade lateral, além do transporte dos carregamentos verticais.

A necessidade de emendas em pilares pré-fabricados de concreto surge da adoção crescente do sistema em edificações de múltiplos pavimentos e das limitações logísticas relativas as dimensões das peças, como transporte e içamento.

Uma solução para o problema é fornecer continuidade ao pilar pré-moldado por meio da ligação de emenda com o emprego de dispositivo metálico. Efetivamente contornando a barreira logística pela subdivisão do elemento em outros menores.

A ABNT NBR9062:2017 [1] prevê a possibilidade da realização de ligações de emenda em pilares prémoldados, mas não fornece parâmetros para caracterizar o comportamento da ligação.

O objetivo principal do trabalho consiste em analisar o desempenho em serviço (rigidez) de ligações por meio de emenda com dispositivo metálico, descrito na ABNT NBR9062:2017 [1], e compará-lo com o de ligações monolíticas para estimativa de um parâmetro de rigidez equivalente do pilar pré-moldado.

Os objetivos secundários do trabalho são:

- Aferir resistência à flexão da ligação;

- Caracterizar as curvas de força-deslocamento e momento-curvatura do sistema, bem como comparálas com a situação de ligação monolítica;

A ligação de emenda por dispositivo metálico é utilizada na literatura internacional, sendo uma ligação que já passou por comprovação experimental. No entanto, o item c da Seção 5.5.3 da ABNT NBR9062:2017 [1] diz que não podem ser feitas extrapolações diretas de ensaios efetuados em outros países. E que podem ser feitas adequações a estes ensaios, desde que consideradas as condições locais e os tipos de materiais e de equipamentos utilizados.

Por isso, são necessários resultados nacionais de ensaios que avaliem o desempenho dessa ligação, principalmente para avaliação do desempenho em serviço visto que a rigidez efetiva desenvolvida é um critério importante de projeto em regiões não-sísmicas.

Este estudo também se justifica pelo fato de ser uma ligação típica e também devido a carência de estudos específicos relacionados a análise da rigidez efetiva da ligação, uma vez que até mesmo em outros países a maior preocupação está relacionada a ductilidade, e não a rigidez da ligação, devido a necessidade de dissipar grandes quantidades de energia originárias de abalos sísmicos.

\section{REVISÃO BIBLIOGRÁFICA}

Projetos e construções eficientes são alcançadas por meio do uso de ligações com desempenho adequado às diferentes situações de carregamento, ambientais e em serviço. O sistema é composto de elementos prémoldados conectados mecanicamente por solda, grauteamento, parafusos, armadura, entre outros. No entanto, as ligações não devem apenas fixar os elementos um ao outro, mas sim garantir a integridade estrutural de todo o conjunto (FIB,2008 [2])

\subsection{Ligações de continuidade em pilares pré-moldados}

No Brasil, convencionalmente, são utilizadas estruturas reticuladas não contraventadas, cuja estabilidade lateral depende da rigidez dos pilares. Portanto, os pilares precisam de continuidade para transmissão de esforços horizontais.

Existem diversas maneiras de se conectar os pilares pré-moldados, sendo que a decisão por uma tipologia sobre outra usualmente depende das condições locais da obra e logística específica de içamento muito mais do que a resistência da ligação propriamente dita. É muito importante que a estabilidade temporária da estrutura não seja colocada em risco através do uso de ligações que dependem de maneira excessiva de atrito, encunhamento ou outras ações físicas de difícil controle [3]. Um exemplo de ligação pilar-pilar de continuidade por meio de chapa metálica e solda é mostrado na Figura 1. 

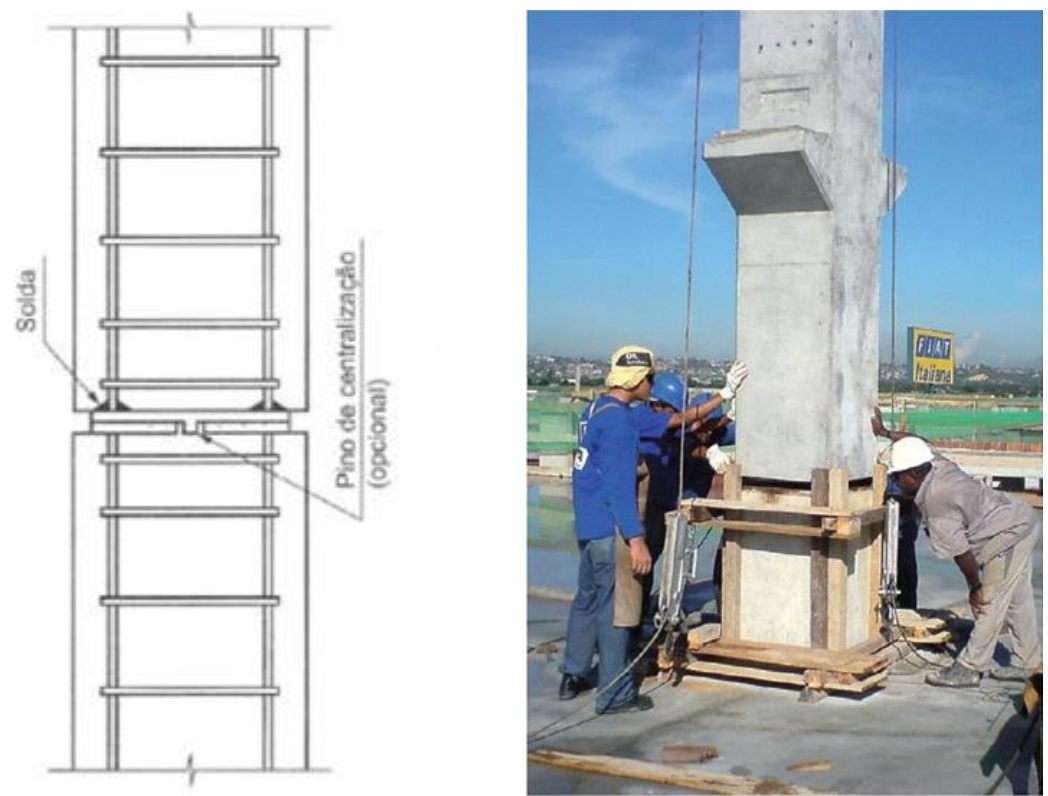

Figura 1: Ligação pilar-pilar soldada com chapa metálica. (Fonte: [1] e [3]).

As ligações pilar-pilar são feitas por engates (acoplamento), solda, parafusos ancorados em elementos pré-moldados diferentes ou pela continuidade da armadura em nós grauteados.

Dispositivos metálicos podem ser utilizados em ligações para transmitir tração e momento fletor entre elementos. A ligação com dispositivos metálicos pode ser utilizada para a ligação entre uma coluna e sua base ou entre duas colunas e apresenta vantagens em relação a custo e sustentabilidade para seções transversais de grandes dimensões $(40 \mathrm{~cm} \times 40 \mathrm{~cm}$ ou maior) devido à solução em chapa metálica apresentar grande desperdício para essas seções. As peças metálicas de ligação também podem ser utilizadas em seções não retangulares.

A Figura 2 mostra um exemplo de ligação com dispositivo metálico similar ao estudado no presente trabalho. É também possível observar a falha do elemento de ligação.
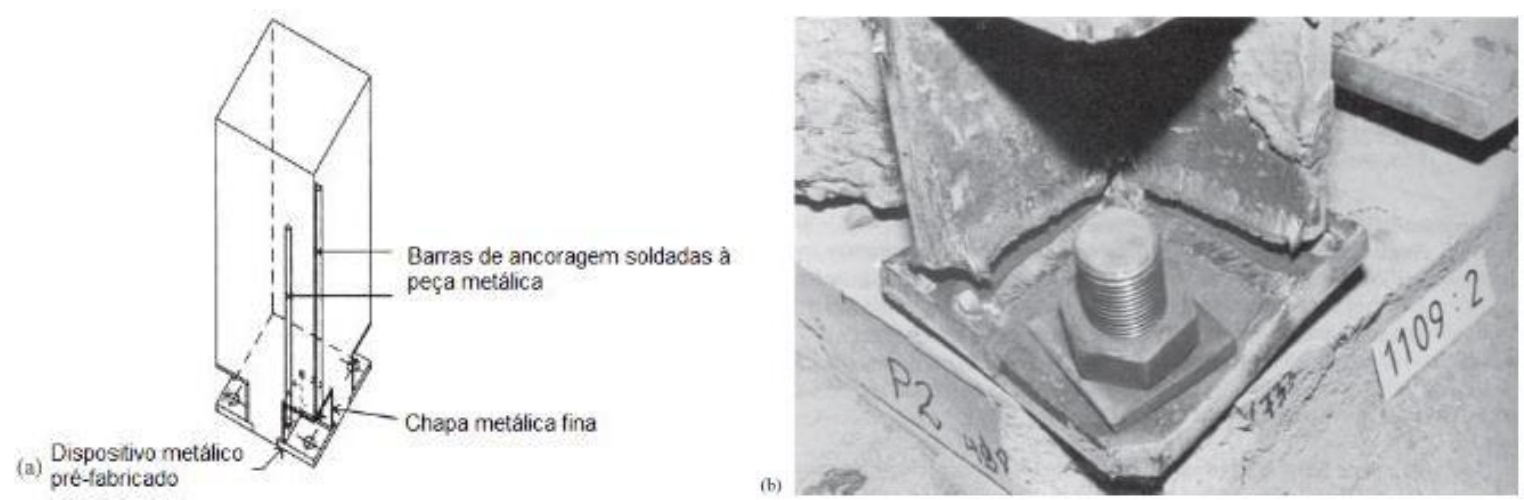

Figura 2: Ligação por meio de dispositivo metálico pré-fabricado: a) componentes da ligação e b) falha do elemento de ligação em um dos cantos da coluna. (Fonte: adaptado de [3]).

Vale ressaltar que a presente pesquisa se limita em estudar a rigidez da ligação entre pilares pré-moldados com $\mathrm{f}_{\text {ck }}$ de $40 \mathrm{MPa}$ com seção retangular de 40x50 cm² com 4 Ф $25 \mathrm{~mm}$ como armadura principal. Todas as barras apresentarão a mesma ligação por meio de sapatas metálicas pré-fabricadas na sua base, de modo a transferir os esforços de maneira adequada. O modelo de referência apresentará as mesmas características, com exceção da ligação que será monolítica. 


\subsection{Pesquisas realizadas}

KINNUNEN [4] realizou diversos ensaios em ligações por meio de dispositivos metálicos (sapatas metálicas pré-fabricadas) para aferir a capacidade resistente, o desempenho em serviço e a equivalência com a ligação monolítica. O intuito era validar o desempenho da ligação para normas europeias e certificar o produto para ser vendido dentro da união europeia. Um dos ensaios realizados foi de flexão pura a 4 pontos com as peças dispostas e conectadas horizontalmente de maneira similar à realizada nesse estudo.

Esse ensaio teve o intuito de analisar a influência na rigidez (local e global) quando utilizada a ligação por meio de sapatas metálicas sendo verificado com os resultados que a rigidez, local e global, em cada seção do pilar analisada foi comparável ao caso de ligação monolítica como pode ser observado na Figura 3.

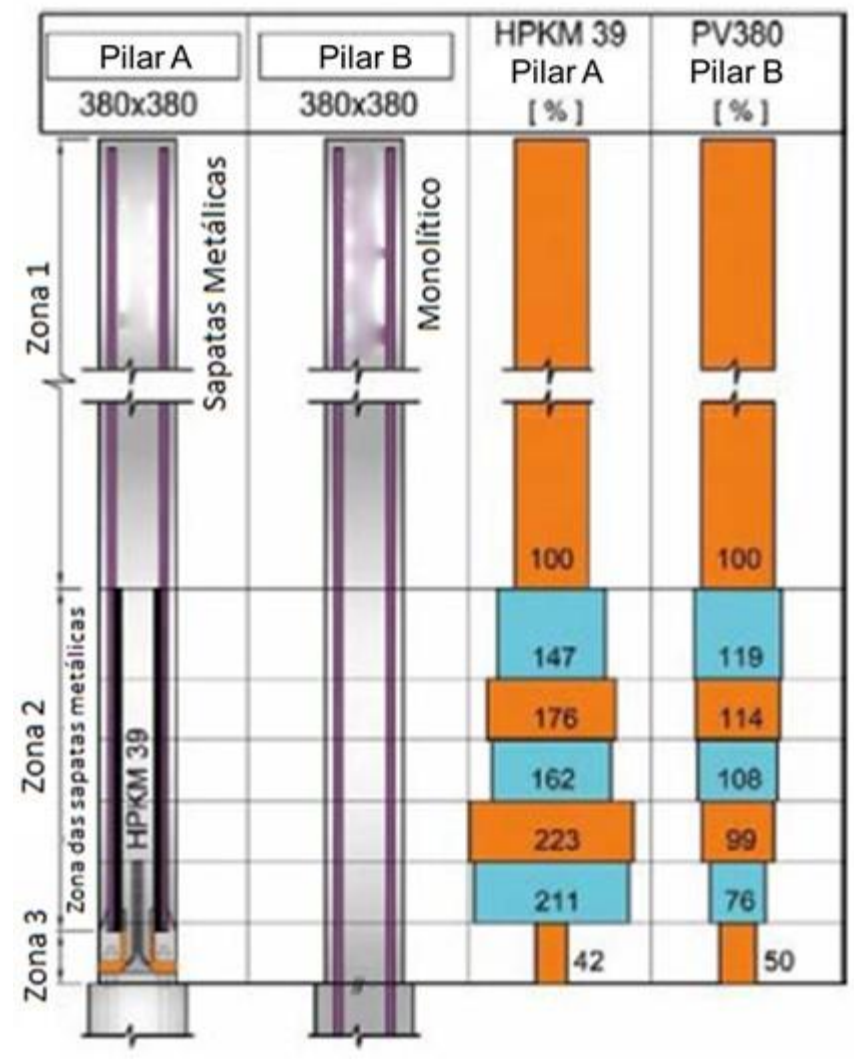

Figura 3: Subzonas de rigidez relativa à flexão entre pilar com ligação monolítica e pilar com ligação através de dispositivos metálicos (sapatas metálicas). (Fonte: adaptado de [4]).

Comparando os pilares A e B, observa-se que na Zona 1 a rigidez é naturalmente idêntica, na Zona 2 a rigidez do pilar com ligação por meio de dispositivos metálicos (também denominados de sapatas metálicas) é bastante superior ao pilar com ligação monolítica devido a sobreposição da armadura principal com as armaduras de ancoragem da sapata metálica e na Zona 3 a rigidez relativa do pilar com ligação por sapatas metálicas é inferior, porém comparável. Isso ocorre devido a redução da seção efetiva de concreto e solicitação excêntrica nas sapatas metálicas dessa região. Quando comparados globalmente a maior rigidez na Zona 2 compensa a rigidez um pouco inferior da Zona 3, sendo que os deslocamentos observados no topo dos pilares foram de 380,7 mm para o pilar com ligação por meio de sapatas metálicas e de 450,2 mm para o pilar com ligação monolítica. KINNUNEN [4] concluiu a partir dos ensaios que as ligações com sapatas metálicas grauteadas apresentaram comportamento compatível com uma ligação monolítica convencional.

O trabalho de BACHEGA [5] apresentou como objetivo caracterizar o comportamento de uma ligação pilar-pilar por meio de luvas mecânicas grauteadas quanto à resistência, rigidez e ductilidade, avaliando e comparando seu desempenho com o elemento monolítico de referência. Foram realizados quatro ensaios de flexão simples pura de protótipos de concreto em escala real, sendo dois segmentados e dois contínuos.

BACHEGA [5] fez isso através de ensaios físicos em escala real de quatro pilares pré-fabricados. Dois eram monolíticos e dois eram segmentados para comparação. Os modelos ensaiados por ele apresentaram seção transversal de $40 \mathrm{~cm} \times 50 \mathrm{~cm}, 4 \mathrm{~m}$ de comprimento total, quatro barras de $25 \mathrm{~mm}$ de diâmetro e um 
vazio central cilíndrico para possível aplicação de esforços normais. O efeito dos esforços normais não foi avaliado nesse estudo. A disposição geral do arranjo de ensaio em laboratório é mostrada na Figura 4.

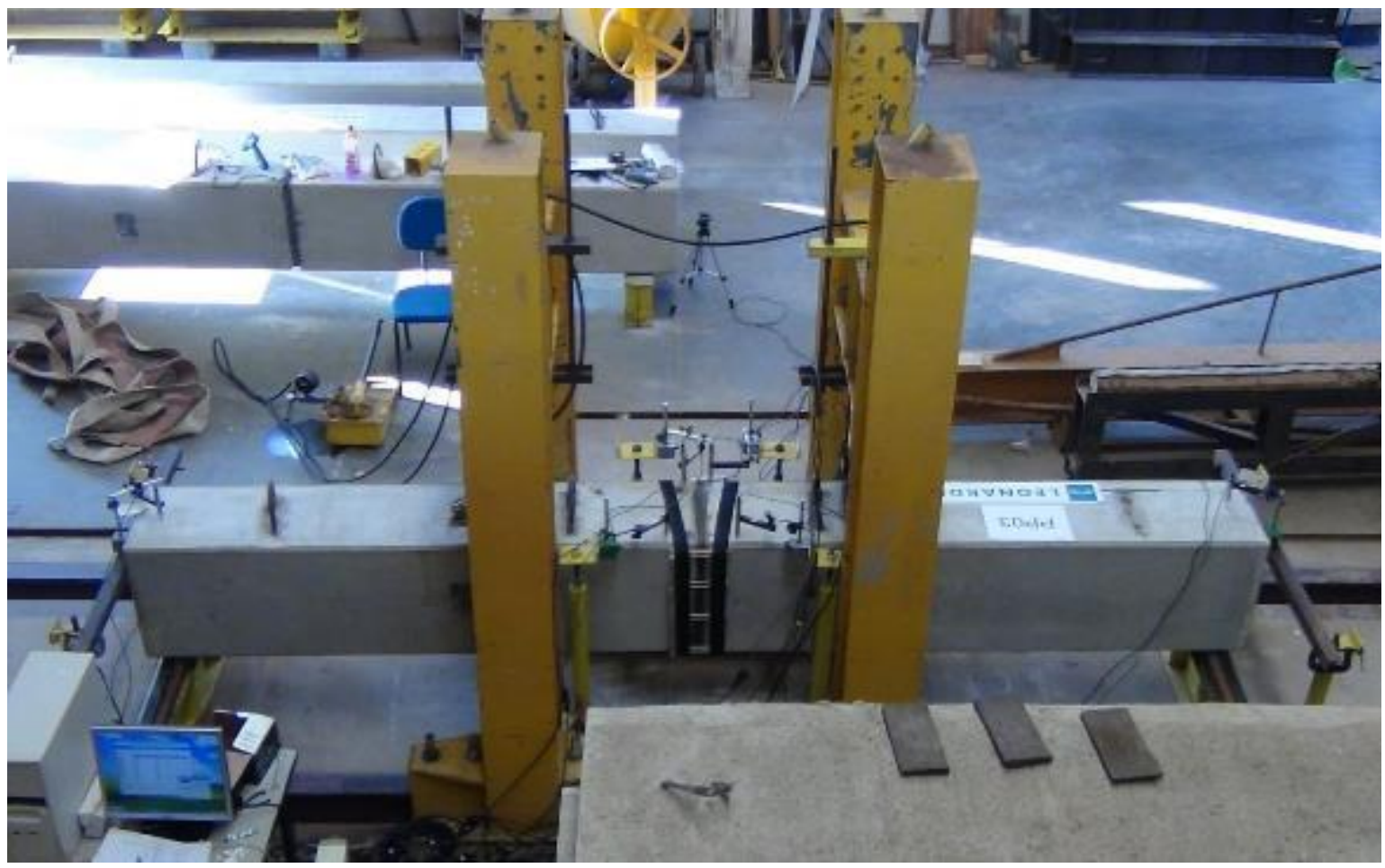

Figura 4: Disposição geral do arranjo de ensaio em laboratório (NETPre/UFSCar). (Fonte: [5]).

Com base na comparação experimental entre os modelos com ligações e os modelos monolíticos, B ACHEGA [5] observou que embora tenha havido uma descontinuidade na região da junta grauteada, com liberação de rotações relativas entre os elementos pré-moldados, os deslocamentos apresentados ao longo dos protótipos pré-moldados foram muito próximos dos deslocamentos obtidos para o elemento monolítico, tendo-se uma boa convergência para todas as fases da relação força $\times$ deslocamento, com equivalência para a rigidez, a resistência e a ductilidade entre as curvas analisadas. Portanto, pode ser admitida a existência de uma equivalência monolítica.

\section{PROGRAMA EXPERIMENTAL}

Nesta seção são apresentados os modelos, a descrição dos ensaios realizados e a caracterização dos materiais empregados.

Vale enfatizar que o presente trabalho faz parte de uma linha de pesquisa em ligações semirrígidas do NETPre (Núcleo de Estudos e Tecnologia em Pré-moldados de Concreto) na UFSCar. Dessa forma, este trabalho é continuação do trabalho desenvolvido em BACHEGA [5] e apresenta projeto dos modelos e metodologia similares para possibilitar melhor análise.

\subsection{Definição dos modelos}

$\mathrm{O}$ estudo sobre o desempenho em serviço da ligação pilar-pilar foi realizado por meio de ensaios físicos em escala real. Dessa forma, foram definidos 2 modelos a serem ensaiados: um modelo monolítico e um modelo segmentado com ligações parafusadas.

O modelo monolítico, definido como MB (monolítico B), foi constituído por uma única peça préfabricada e teve a função de servir como referência para a análise do modelo com ligações. O modelo segmentado, definido como LB-PAR (Ligação B - Parafusado), foi constituído por dois elementos préfabricados distintos ligados por meio de elementos metálicos parafusados e solidarizados com o emprego de graute. 
O comportamento dos pilares foi analisado tanto localmente na ligação quanto globalmente na peça como um todo.

Ambos os modelos foram projetados com seção transversal de $40 \mathrm{~cm} \times 50 \mathrm{~cm}, 4 \mathrm{~m}$ de comprimento total e quatro barras de $25 \mathrm{~mm}$ de diâmetro. O modelo segmentado finalizado, além disso, apresenta sapatas metálicas e parafusos (33 mm de diâmetro) que foram utilizados para unir as duas peças. Esse detalhe pode ser visualizado na Figura 5.

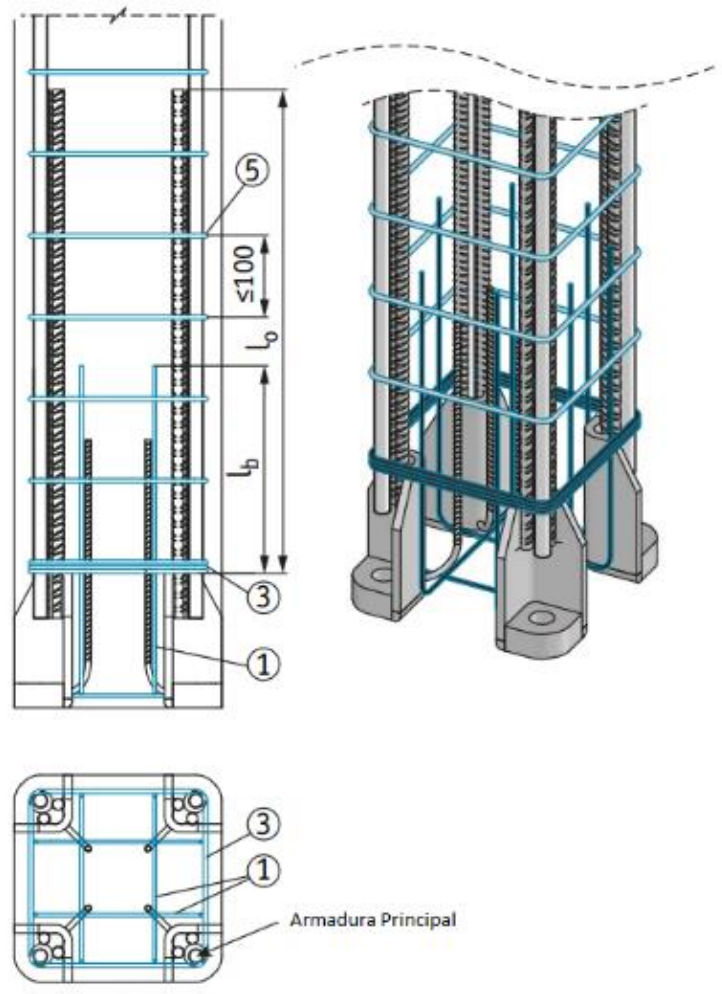

Figura 5: Detalhe das sapatas metálicas presentes no modelo segmentado. (Fonte: adaptado de [6]).

\subsection{Ensaios experimentais}

Os modelos foram ensaiados à flexão pura a 4 pontos com os elementos dispostos horizontalmente, sendo esta condição distinta a de um pilar convencional que possui esforços normais além dos de flexão. A força normal não foi aplicada aos pilares. No entanto, é convencional que pilares de galpões com cobertura e fechamento leves (cobertura e fechamento lateral com telhas metálicas) apresentem a predominância de momentos fletores em detrimento ao esforço normal de compressão, sendo, dessa forma, dimensionados praticamente como vigas em balanço. Assim, os ensaios realizados em flexão pura representaram, portanto, uma aproximação ao comportamento real de um pilar pré-moldado de galpão. O esquema de ensaio pode ser observado na Figura 6. 


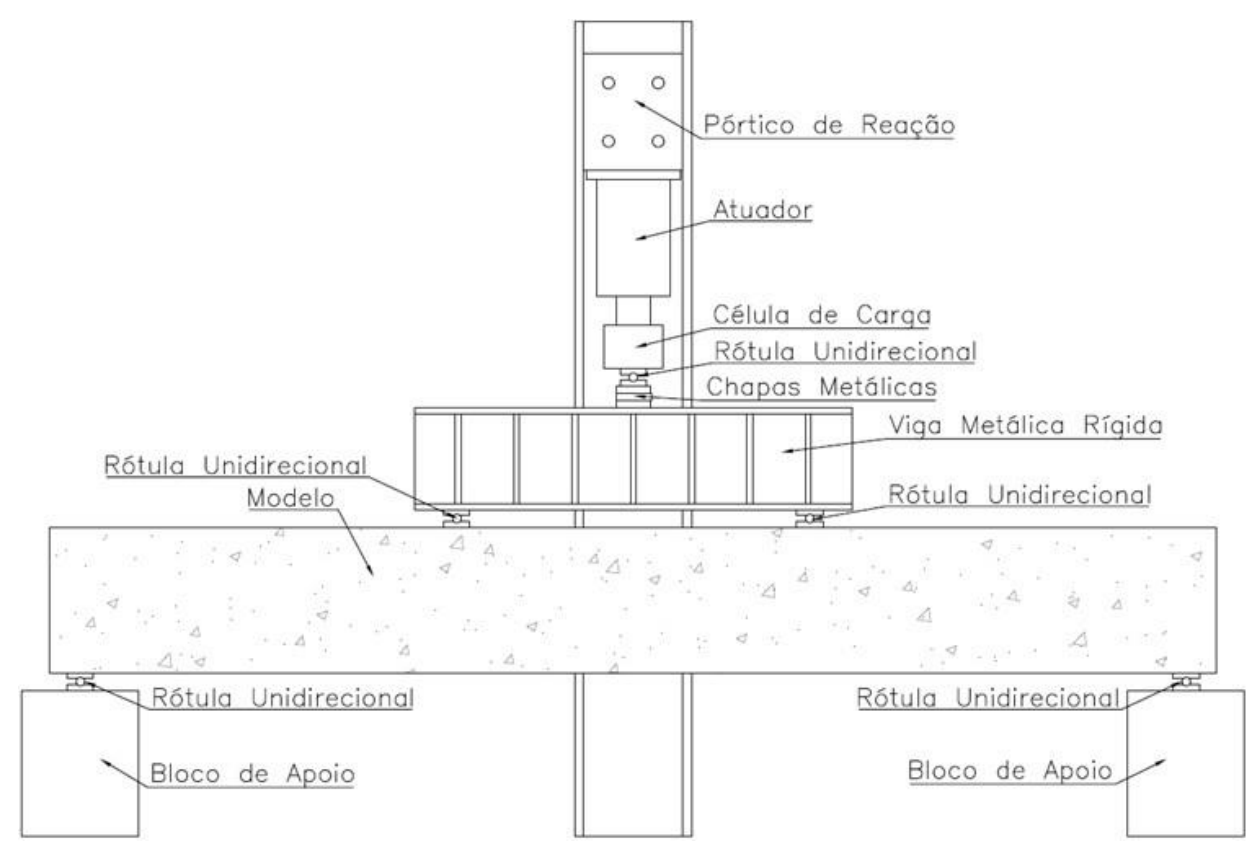

Figura 6: Esquema de ensaio realizado - flexão a 4 pontos. (Fonte: o autor).

Esse arranjo tem como objetivo fazer o modelo se aproximar do esquema de carregamento e distribuição de esforços internos mostrados na Figura 7.
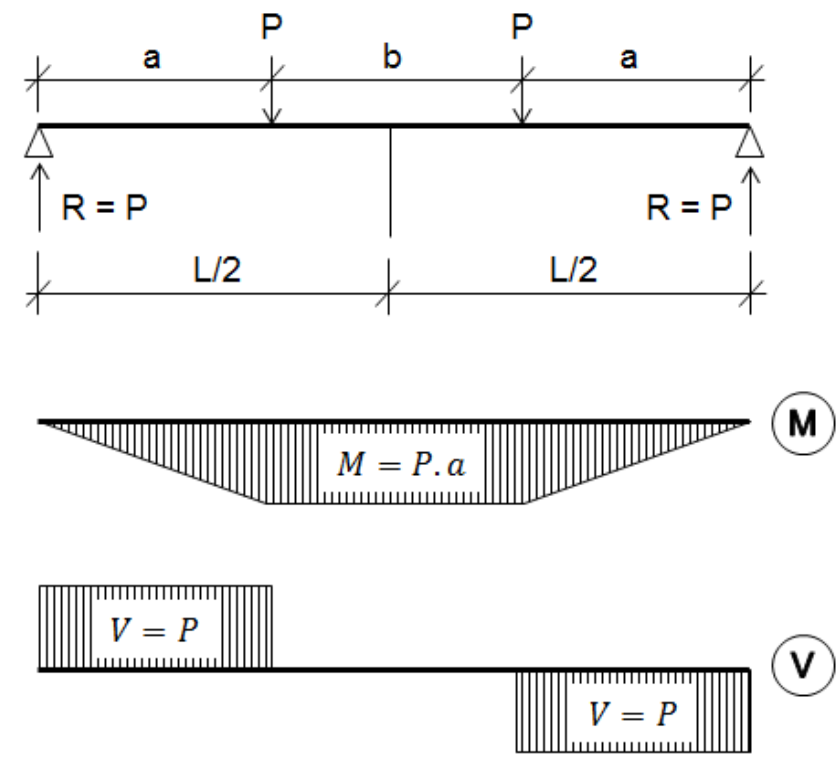

Figura 7: Esquema estrutural do ensaio de flexão a 4 pontos

Desta maneira, na região central da ligação a peça está submetida exclusivamente a esforços de flexão, o que permite a análise dessa variável sem a interferência de outros mecanismos.

Para a realização dos ensaios, foram empregados transdutores para a obtenção de leituras de deslocamentos verticais no centro e nas extremidades, transdutores para a medição de deslocamentos horizontais na região da ligação (totalizando dez transdutores), extensômetros elétricos de base removível para a obtenção de leituras de deformação (somando quatro extensômetros) e uma célula de carga de capacidade de $1000 \mathrm{kN}$, para a obtenção de leituras da força aplicada no modelo.

O posicionamento dos transdutores (TD) utilizados na montagem do modelo MB está mostrado na Figura 8. 


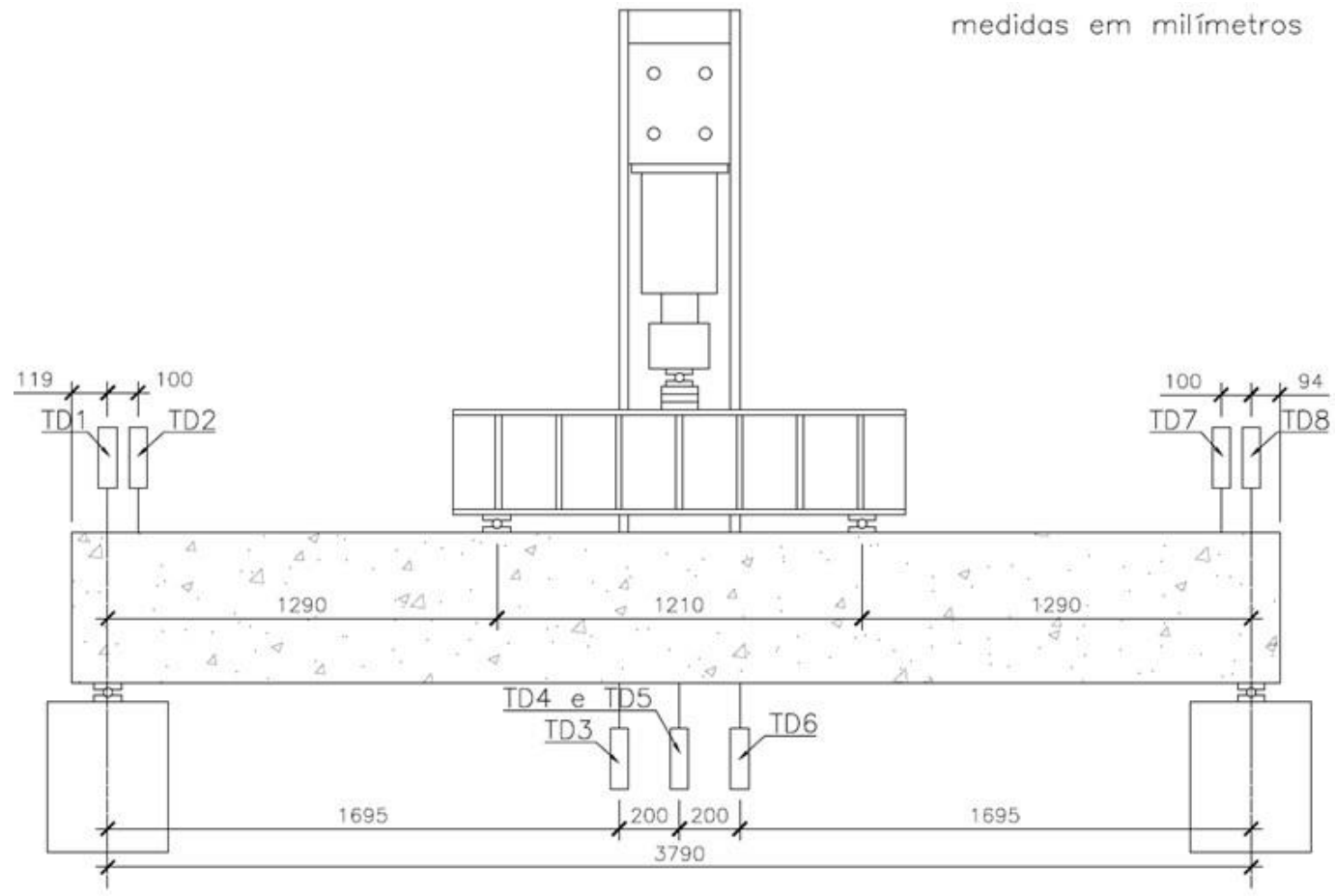

Figura 8: Posicionamento dos transdutores e disposição final do experimento para Modelo MB. (Fonte: o autor).

O posicionamento dos transdutores (TD) utilizados na montagem do modelo segmentado LB-PAR está mostrado na Figura 9, sendo possível observar pequenas diferenças quanto ao posicionamento dos instrumentos, em relação ao modelo monolítico ilustrado na Figura 8.

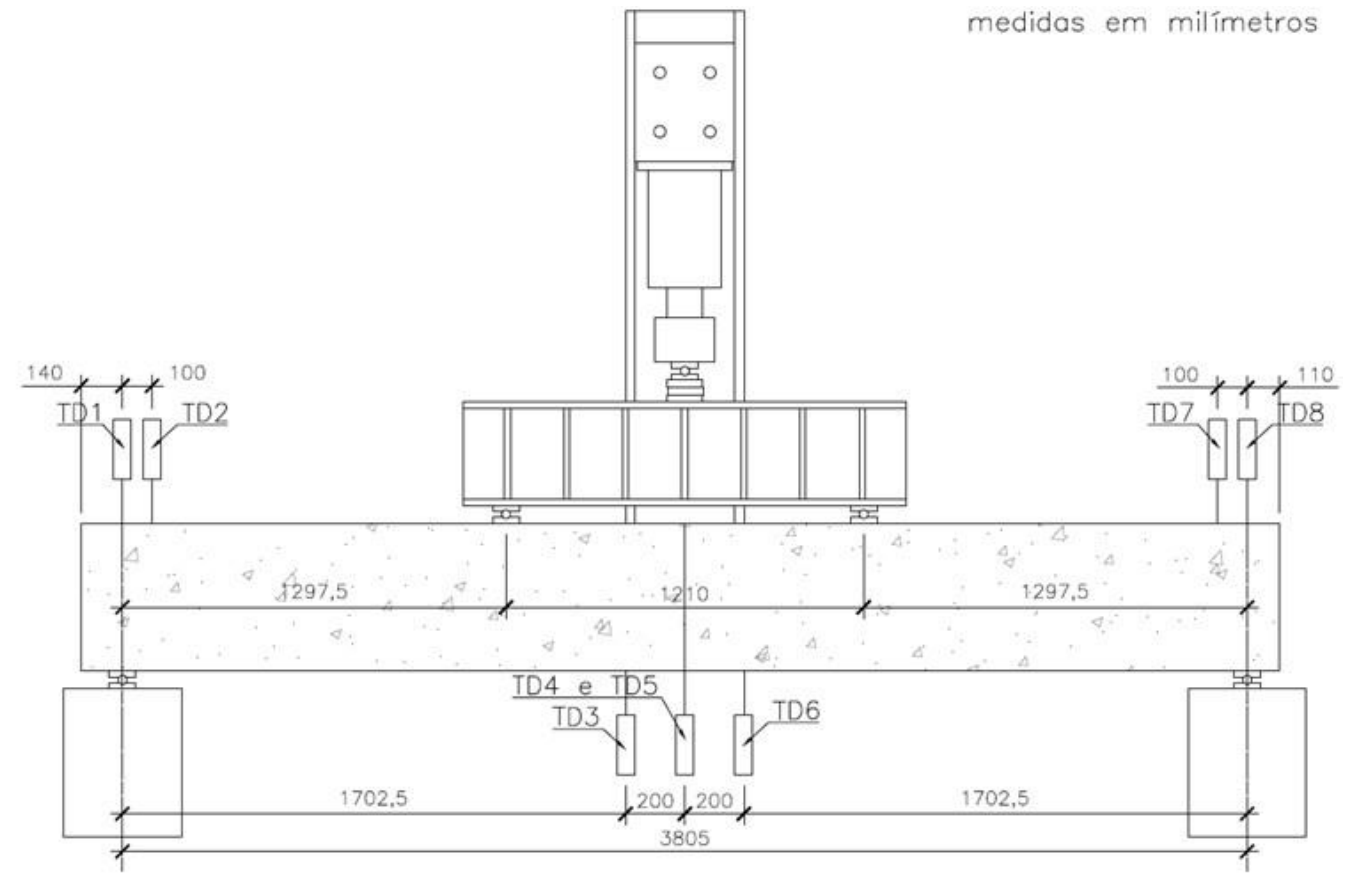

Figura 9: Instrumentação e disposição final do experimento para Modelo LB-PAR. (Fonte: o autor).

O detalhe da instrumentação lateral, com os extensômetros de base removível (EB) e os transdutores e o posicionamento em planta dos transdutores centrais podem ser observados na Figura 10. 

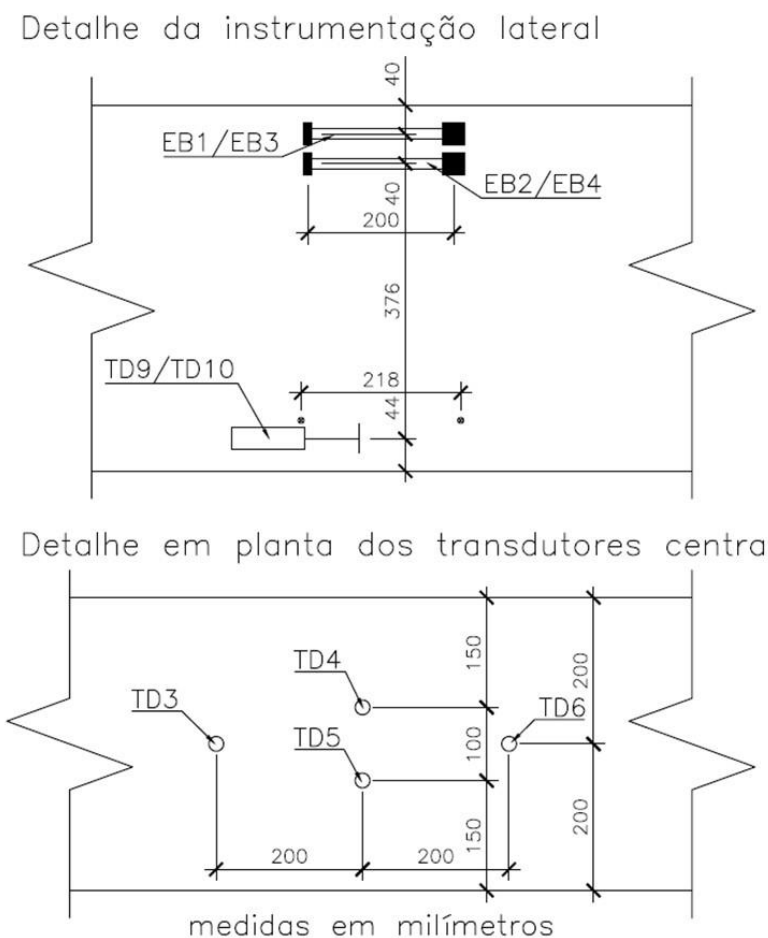

Figura 10: Detalhes adicionais da instrumentação. (Fonte: o autor).

Na Figura 11 pode-se observar o modelo MB e sua configuração de fissuração após a realização do ensaio. Na Figura 12 é possível observar a instrumentação utilizada no modelo MB. Vale observar que foram empregadas rótulas em cada apoio do pilar e também em cada extremidade da viga de transferência de força.

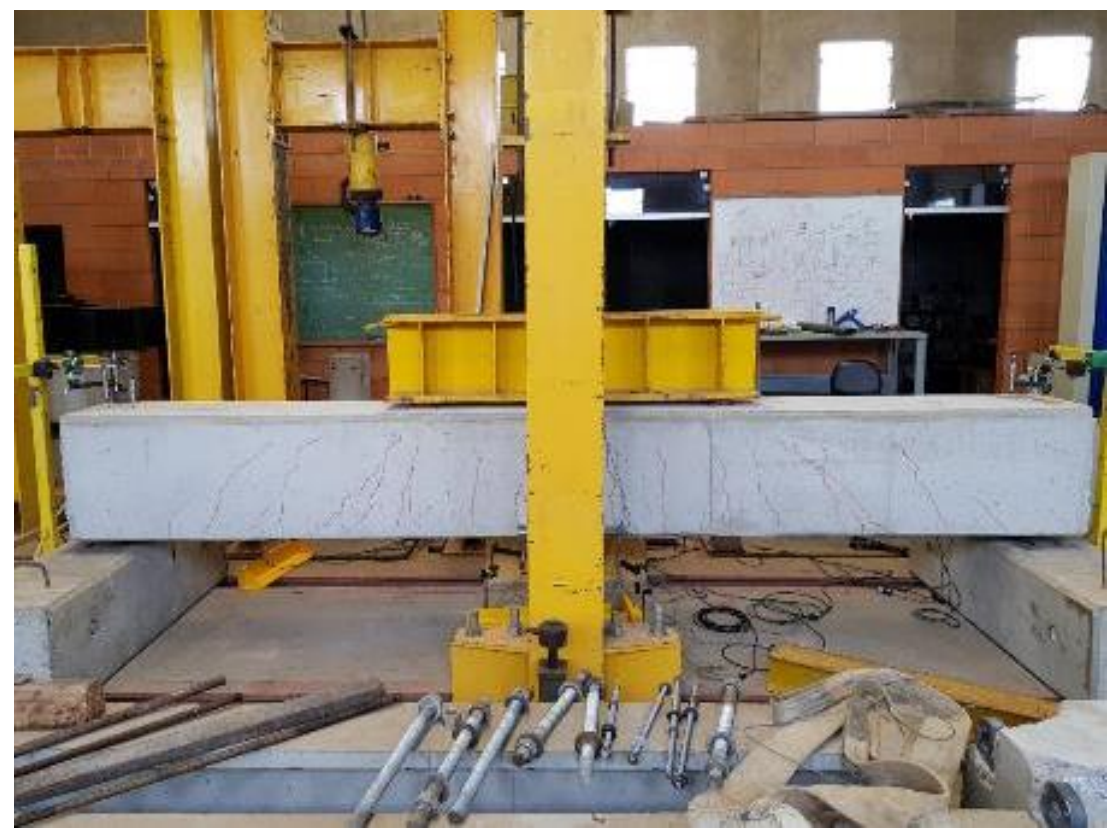

Figura 11: Configuração da fissuração do Modelo MB após ensaio de flexão. (Fonte: o autor). 


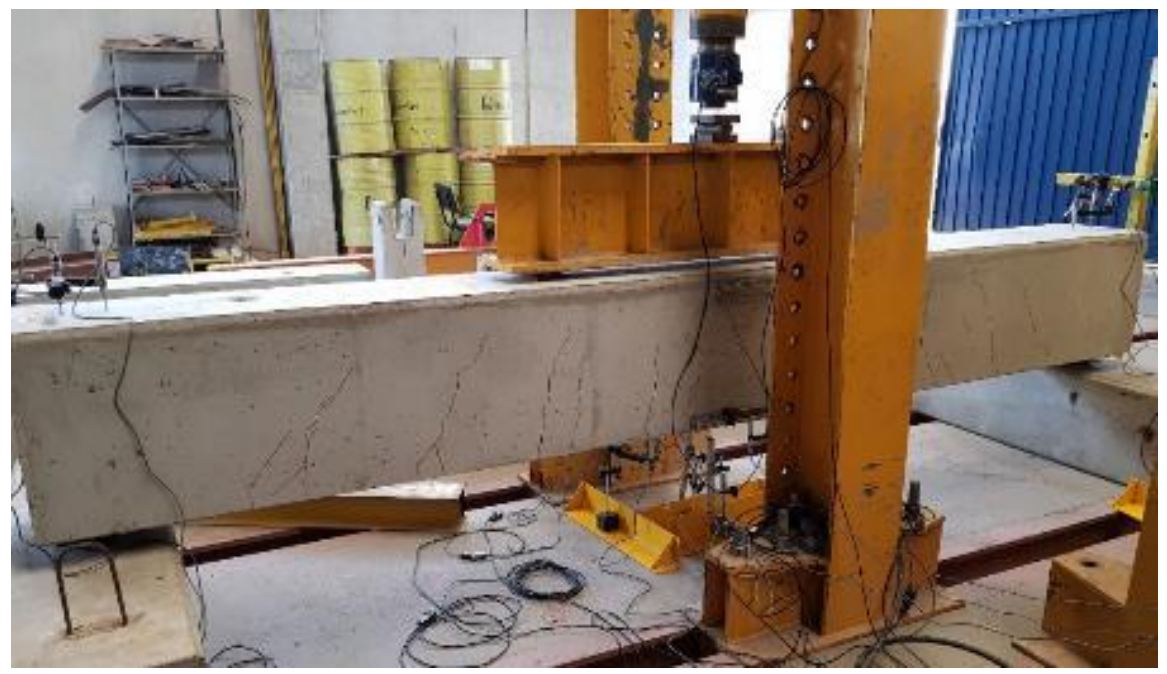

Figura 12: Visão geral da instrumentação no ensaio do Modelo MB. (Fonte: o autor).

O modelo LB-PAR é mostrado após ensaio na Figura 13.

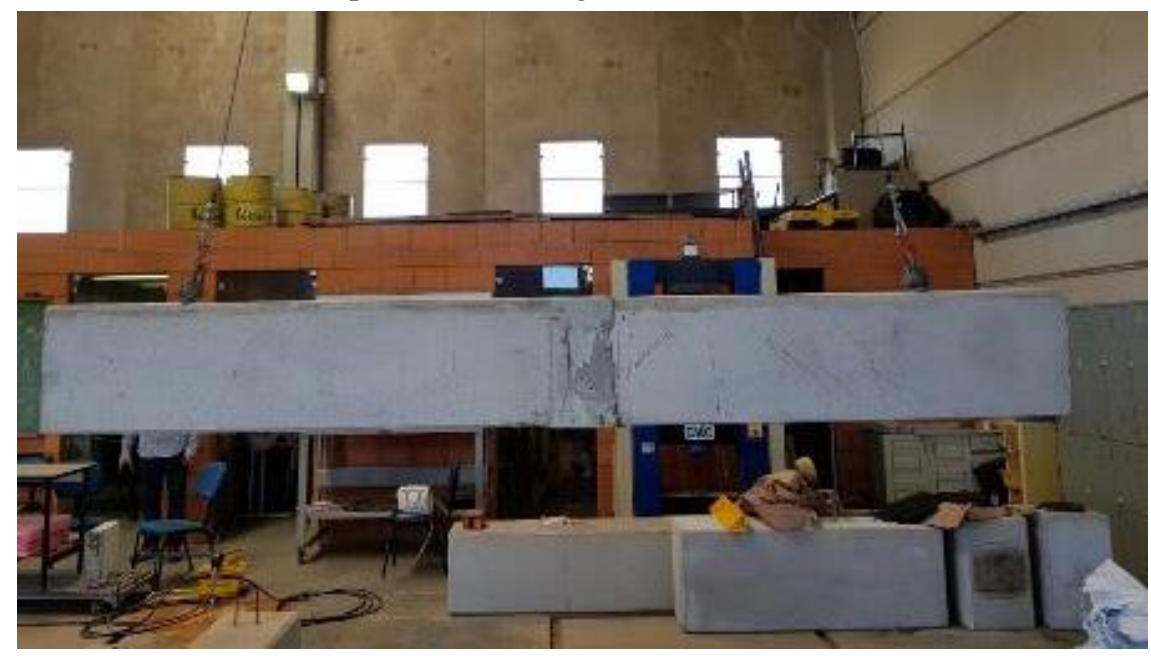

Figura 13: Modelo LB-PAR após ensaio. (Fonte: o autor).

\subsection{Metodologia experimental}

A metodologia experimental se baseou na determinação da rigidez equivalente da ligação por meio da obtenção das leituras de deslocamentos verticais dos modelos.

A flecha foi determinada a partir dos valores de deslocamento verticais obtidos no centro do modelo descontando os valores de deslocamentos obtidos nos apoios.

Um parâmetro importante para análise do desempenho do modelo é o momento fletor limite de escoamento. Esse valor corresponde ao momento referente ao surgimento de tensão na armadura igual a $90 \%$ da tensão de escoamento da mesma. $\mathrm{O}$ momento fletor limite de escoamento para o modelo de referência MB foi determinado por meio da Equação 1:

$$
M_{y, \text { lim }}=0,9 \cdot d \cdot A_{s} \cdot f_{y k}=0,9 \cdot 456,2 \cdot 982 \cdot 600=241,9 \mathrm{kNm}
$$

Sendo,

$M_{y, \text { lim }}$ o momento limite de escoamento do modelo;

$d$ a altura útil do modelo de concreto (456,2 $\mathrm{mm})$;

$A_{s}$ a área de aço existente na parte tracionada da seção $\left(982 \mathrm{~mm}^{2}\right)$;

$f_{y k}$ a resistência de escoamento característica do aço (valor fornecido pelo fabricante de $600 \mathrm{MPa}$ ); 
Para analisar o desempenho em serviço das peças foi determinado o coeficiente de rigidez efetivo para cada estágio de carregamento. Isso possibilitou a comparação da deformabilidade entre os modelos ao longo de todo o ensaio. O coeficiente de rigidez EI efetivo foi obtido através da flecha, da força atuante e da geometria do modelo, da seguinte maneira:

$$
(E I)_{e f}=\frac{P \cdot a}{24 f_{1}}\left(3 L^{2}-4 a^{2}\right)
$$

\section{Sendo:}

$(E I)_{e f}:$ coeficiente de rigidez EI efetivo;

$P$ : força aplicada em cada um dos pontos pelo atuador; PAR);

a: distância entre a força aplicada e o apoio do modelo (1290 mm para MB e 1297,5 mm para LB-

$L$ : distância entre apoios (3790 mm para MB e 3805 mm para LB-PAR);

$f_{1}$ : flecha central corrigida do modelo;

A curvatura na região central do modelo foi determinada a partir da relação entre momento fletor e rigidez da ligação, da seguinte maneira:

$$
\left(\frac{1}{r}\right)=\frac{\mathrm{M}}{(E I)_{e f}}=\frac{24 f_{1}}{\left(3 L^{2}-4 a^{2}\right)}
$$

Sendo:

$\left(\frac{1}{r}\right)$ : a curvatura na região central do modelo;

M: o momento fletor aplicado na região central;

\subsection{Caracterização dos materiais}

O modelo monolítico (MB) é composto apenas pelo concreto utilizado na fábrica durante a execução do protótipo e o modelo parafusado (LB-PAR) apresenta dois elementos com concreto do mesmo lote do utilizado na confecção do modelo monolítico.

Foram moldados cinco corpos de prova do concreto utilizado na fábrica para concretagem dos protótipos e quatro corpos de prova do graute utilizado na junta para montagem da ligação.

Dois corpos de prova do concreto foram ensaiados à compressão simples para estimativa inicial da resistência. Os resultados podem ser observados na Tabela 1.

Tabela 1: Ensaio de compressão simples do concreto.

\begin{tabular}{cll}
\hline CORPO DE PROVA & FORÇA MÁXIMA (N) & RESISTÊNCIA À COMPRESSÃO (MPa) \\
\hline CP1 & $280.716,09$ & 35,74 \\
\hline CP2 & $277.829,22$ & 35,37 \\
\hline
\end{tabular}

A partir dos resultados foi possível determinar um valor médio para a resistência à compressão do concreto como sendo 35,55 MPa para a realização do ensaio de módulo de elasticidade.

Na Tabela 2 estão apresentados os resultados do módulo de elasticidade do concreto, bem como as resistências efetivas à compressão obtidas para os corpos de prova.

Tabela 2: Ensaio de módulo de elasticidade do concreto.

\begin{tabular}{cll}
\hline CORPO DE PROVA & RESISTÊNCIA EFETIVA (MPa) & MÓDULO DE ELASTICIDADE (GPa) \\
\hline CP3 & 35,19 & 26,66 \\
\hline CP4 & 28,45 & 27,97 \\
\hline CP5 & 29,22 & 26,42 \\
\hline
\end{tabular}


Os mesmos ensaios foram repetidos para o graute, porém com quatro corpos de prova em vez de cinco. O resultado do ensaio de compressão simples do graute encontra-se na Tabela 3 e os resultados dos ensaios de módulo de elasticidade estão apresentados na Tabela 4.

Tabela 3: Ensaio de compressão simples do graute.

\begin{tabular}{cll}
\hline CORPO DE PROVA & FORÇA MÁXIMA (kN) & RESISTÊNCIA À COMPRESSÃO (MPa) \\
\hline CP1 & 621,5067 & 77,6 \\
\hline
\end{tabular}

Tabela 4: Ensaio de módulo de elasticidade do graute.

\begin{tabular}{clc}
\hline CORPO DE PROVA & RESISTÊNCIA EFETIVA (MPa) & MÓDULO DE ELASTICIDADE (GPa) \\
\hline CP2 & 67,06 & 33,27 \\
\hline CP3 & 66,26 & 35,01 \\
\hline CP4 & 76,44 & 34,75 \\
\hline
\end{tabular}

\section{DESENVOLVIMENTO E ANÁLISE}

Como mencionado, foram realizados dois ensaios em escala real, sendo ensaiado primeiramente o modelo MB (Monolítico B) e em seguida o modelo LB-PAR (Ligação B - Parafusado). Os resultados desses ensaios foram comparados com os quatro modelos estudados por BACHEGA [5], nomeados da seguinte maneira: MA-1 (Monolítico A - Primeiro Modelo), MA-2 (Monolítico A - Segundo Modelo), LA-LG1 (Ligação A Luva Grauteada - Primeiro Modelo) e LA-LG2 (Ligação A - Luva Grauteada - Segundo Modelo). O modelo LB-PAR passou por dois ciclos de carregamento para reduzir o risco de dano aos equipamentos de instrumentação utilizados, os quais foram transferidos para a parte superior do modelo.

Os gráficos força versus deslocamento central normalizados para comparação da curva entre todos estes modelos estão apresentados na Figura 14.

O comportamento dos modelos na região linear até próximo de $80 \%$ da força relativa ao momento limite de escoamento estão semelhantes como esperado e auxilia na validação dos dados experimentais obtidos. O modelo MB apresentou comportamento bastante próximo dos modelos de BACHEGA [5] durante todo o ensaio. Já o modelo LB-PAR apresentou queda de rigidez para valores de força próximos a $80 \%$ da força relativa ao momento limite de escoamento.

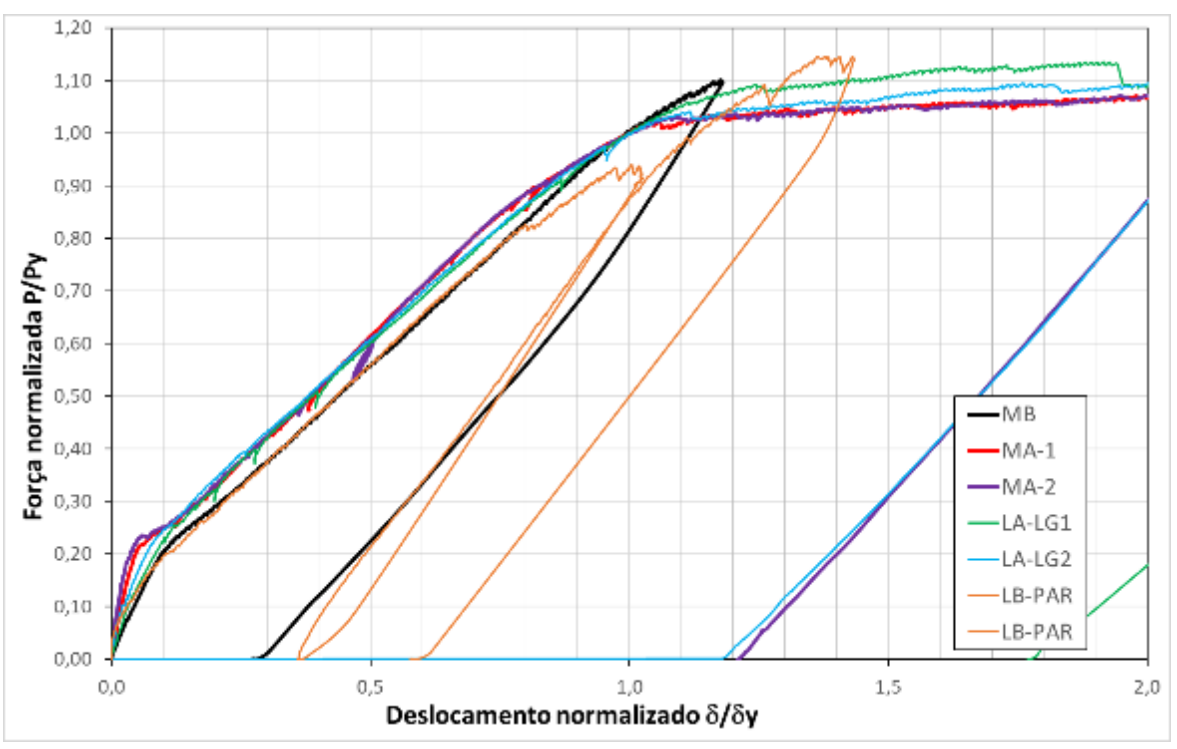

Figura 14: Gráficos força versus deslocamento normalizado para os modelos ensaiados neste trabalho (MB e LB-PAR) e para os modelos da pesquisa de BACHEGA [5] (MA-1, MA-2, LA-LG1 e LA-LG2). (Fonte: o autor). 
Para o modelo MB o momento limite de escoamento implica em uma força $\mathrm{P}$ aplicada igual a $187,5 \mathrm{kN}$. Os resultados isolados e não normalizados obtidos nos ensaios para a curva força versus deslocamento central são apresentados na Figura 15. Esses resultados já foram corrigidos para considerar a translação e a rotação de corpo rígido do modelo de forma global, já que esses deslocamentos não implicam em esforços internos. Assim, a flecha corrigida foi obtida a partir das leituras dos transdutores centrais descontando as leituras dos transdutores posicionados nos apoios.

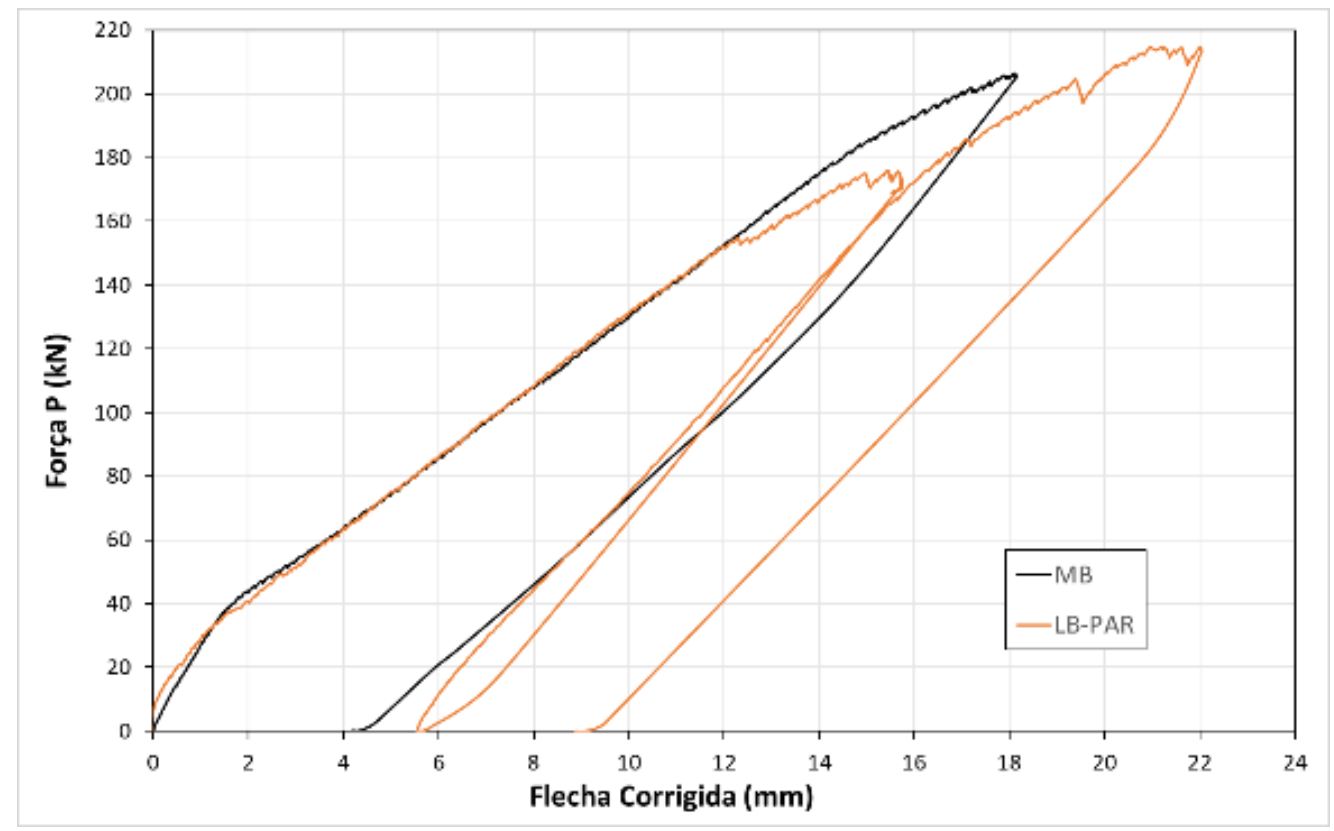

Figura 15: Gráfico força versus deslocamento central corrigido para os modelos MB e LB-PAR. (Fonte: o autor).

Conforme observado na Figura 15, as retas apresentaram comportamento similar até a força de $154 \mathrm{kN}$, atingindo a tensão de $493 \mathrm{MPa}$ na armadura. A partir desse valor o modelo com ligação parafusada apresentou queda de rigidez e abertura de fissura excessiva. Isso ocorreu devido a impossibilidade de impedir o escorregamento da armadura na região da ligação, mesmo com a utilização de barras de maior diâmetro no modelo parafusado do que na situação monolítica. Assim, devido a abertura excessiva da fissura observada com carga próxima de $170 \mathrm{kN}$ (ilustrada na Figura 16), optou-se pelo descarregamento do modelo, sendo posteriormente realizado novo carregamento até sua ruína. Dessa forma, observou-se que durante o primeiro carregamento não houve escoamento da armadura da ligação, apenas perda de aderência aço concreto evidenciada pelo escorregamento da armadura. Com isso, no segundo carregamento, a ligação continuou no regime elástico, apresentando deformações maiores do que as obtidas no primeiro carregamento. 


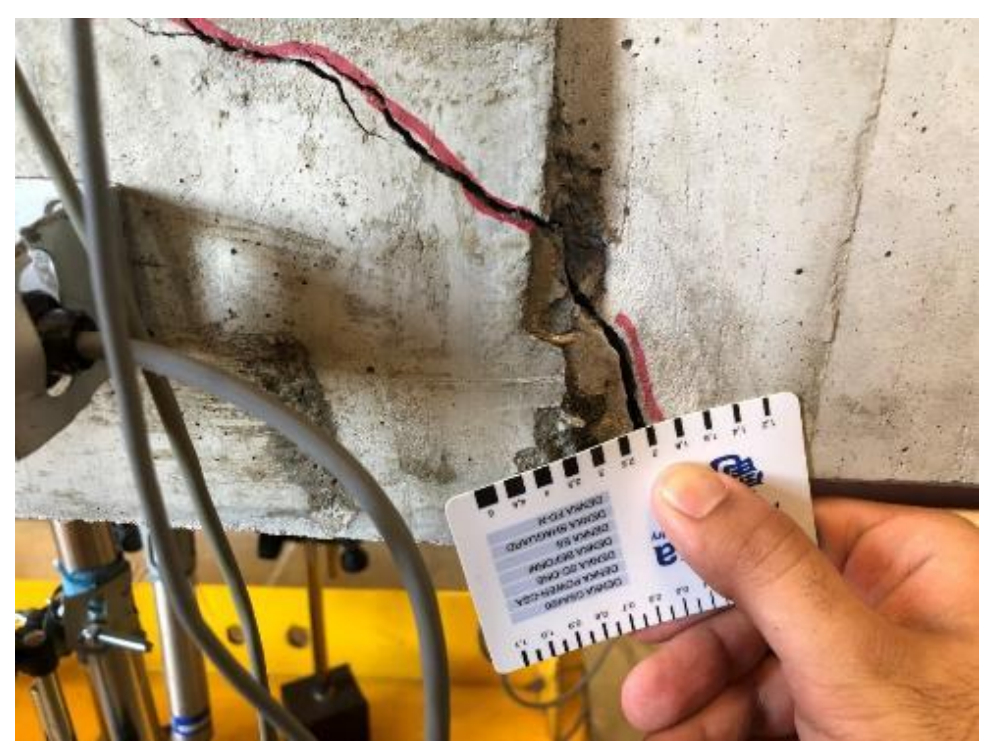

Figura 16: Abertura da fissura no momento do primeiro descarregamento. (Fonte: o autor).

O gráfico momento fletor versus deslocamento central corrigido está apresentado na Figura 17 para ambos os modelos. Esse gráfico possibilita observar a correlação mais direta entre o momento fletor atuante na viga e os deslocamentos desenvolvidos.

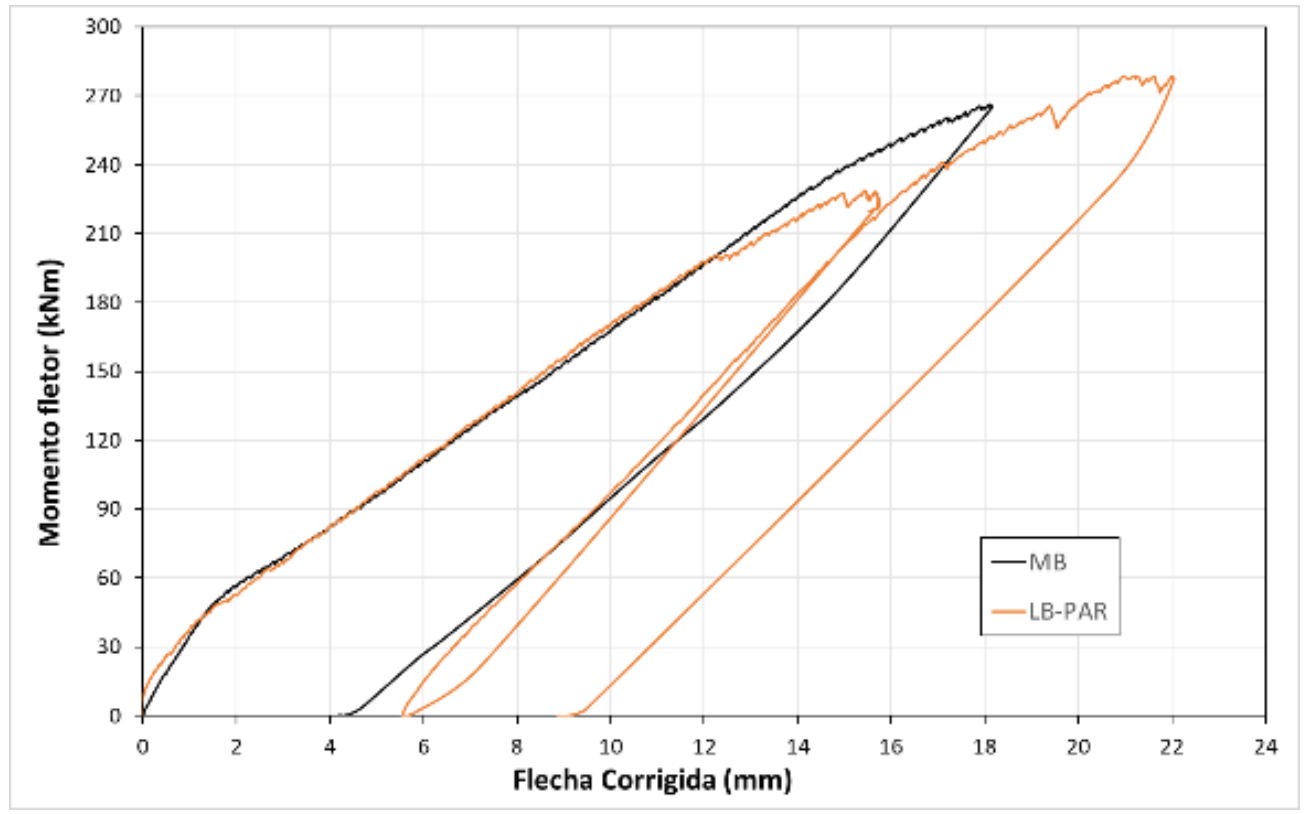

Figura 17: Gráfico momento versus deslocamento central corrigido para os modelos MB e LB-PAR. (Fonte: o autor).

Outro resultado notável foi obtido por meio dos gráficos momento fletor versus curvatura (determinada considerando a seção central do vão). Esses valores também já estão corrigidos para considerar a movimentação de corpo rígido apresentada pelos modelos. Os gráficos podem ser observados na Figura 18. 


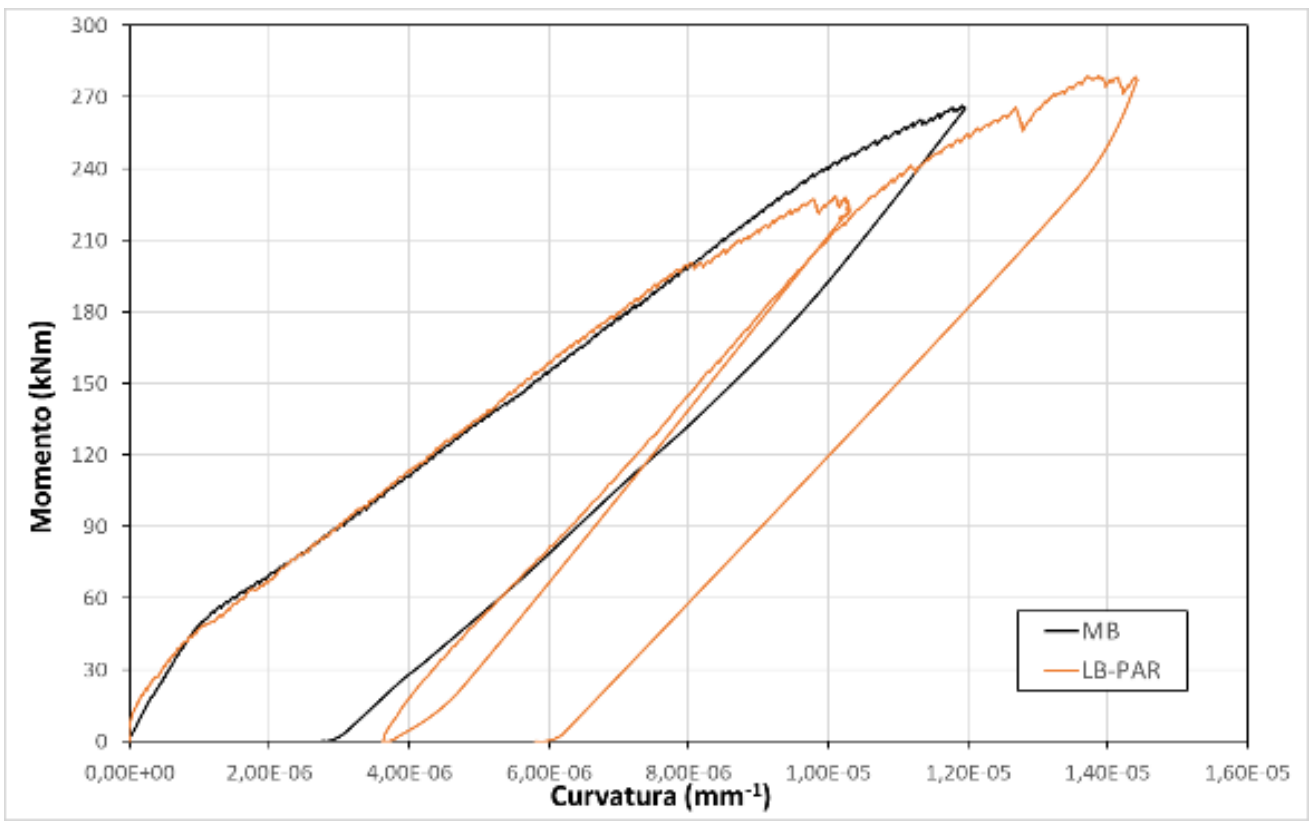

Figura 18: Gráfico momento fletor versus curvatura central corrigido para os modelos MB e LB-PAR. (Fonte: o autor).

Para o modelo MB a curvatura referente ao momento fletor limite de escoamento foi de $1,013 \cdot 10^{-5}$ e para o modelo LB-PAR a curvatura referente ao mesmo momento fletor foi de $1,133 \cdot 10^{-5}$. Isso significa que houve redução de $10,6 \%$ de rigidez do modelo LB-PAR em relação ao modelo MB para esse momento fletor atuante na peça.

\section{CONSIDERAÇÕES FINAIS}

A partir do estudo realizado pôde-se concluir que o modelo com ligação parafusada LB-PAR apresentou comportamento bastante próximo do modelo monolítico de referência MB até cerca de $80 \%$ da força relativa ao momento fletor limite de escoamento. Essa diferença de comportamento ocorre em situações de pilares em que o esforço predominante corresponde ao momento fletor, como no caso de postes e galpões com cobertura e fechamento leves.

Com os ensaios observou-se que durante o primeiro carregamento ocorreu o escorregamento das armaduras da ligação, com abertura de fissura excessiva, o que resultou na perda de rigidez da ligação. Vale ressaltar, que se optou pelo descarregamento devido a fissuração do modelo, entretanto, não houve o escoamento das armaduras da ligação, não afetando sua ductilidade. Dessa forma, ao realizar o segundo carregamento, a ligação continuou a se comportar no regime elástico, atingindo maiores deformações do que as evidenciadas no primeiro carregamento.

Assim, pode-se concluir que o desempenho da ligação estudada foi satisfatório, sendo possível sua utilização em edificações onde o efeito de segunda ordem é desprezível. No caso de edifícios altos, em que existe a presença de momentos fletores e esforço normal não foi identificada restrição que cause preocupação quanto seu uso corrente, uma vez que o estudo realizado correspondeu a uma situação crítica, ou seja, mais desfavorável em relação a distribuição dos esforços na estrutura.

Em situações específicas, onde são empregados pilares esbeltos com pé-direito elevado submetidos a cargas industriais, em que o efeito de segunda ordem é significativo, ou seja, quando os efeitos de segunda ordem representarem acréscimo superior a 10\% nas reações e nas solicitações relevantes na estrutura (de acordo com a NBR 6118 [7]), por exemplo em galpões com pontes rolantes industriais, seria importante considerar o efeito da rigidez da ligação na base do pilar (considerar mola na base do pilar) ou limitar a tensão na armadura abaixo de $80 \%$ de sua tensão de escoamento. Assim, nesse caso seria necessário maior estudo quanto a deformabilidade da ligação e sua calibração para a consideração em projeto. 


\section{BIBLIOGRAFIA}

[1] ASSOCIAÇÃO BRASILEIRA DE NORMAS TÉCNICAS (ABNT), NBR 9062 - Projeto e execução de estruturas de concreto pré-moldado, Rio de Janeiro, 2017.

[2] FIB GUIDE TO GOOD PRACTICE, Structural Connections for Precast Concrete Buildings, 2008, 360p, Task Group 6.2, Commission 6.

[3] ELLIOTT, K. S., JOLLY, C. K., Multi-storey Precast Concrete Framed Structures, 2. ed., 760p., West Sussex, Wiley Blackwell, 2013.

[4] KINNUNEN, J., "ETA tests and design of HPKM Column Shoe Connections", Procedia Engineering, v. 172, pp. 521-528, Feb. 2017.

[5] BACHEGA, L. A. Estudo da continuidade de Elementos Pré-Moldados com Emendas por Luvas Grauteadas. 2018. 159 p. Tese (Doutorado em Estruturas e Construção Civil) - Departamento de Engenharia Civil, Universidade Federal de São Carlos, São Carlos, 2018.

[6] PEIKKO GROUP, https://media.peikko.com/file/dl/i/lhtR6A/2P2ddfwoa6hpzpPJFRoYRg/ HPKMColumnShoePeikkoGroup5-2014, Acessado em: 02 de agosto de 2019.

[7] ASSOCIAÇÃO BRASILEIRA DE NORMAS TÉCNICAS (ABNT), NBR 6118: Projeto de Estruturas de Concreto: Procedimentos. Rio de Janeiro, 2014.

\section{ORCID}

João Lucas Figueiredo Paes de Barros

https://orcid.org/0000-0002-1354-5902

Bruna Catoia

https://orcid.org/0000-0003-3847-4263

Marcelo de Araújo Ferreira

https://orcid.org/0000-0001-5175-2171 